\title{
Cândido da Silva Dias: meio século como pesquisador
}

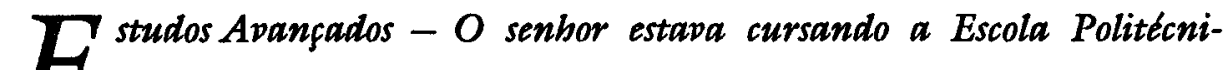 H ca e foi para a Faculdade de Filosofia, Ciencias e Letras da USP quando esta foi criada. Como foi a fase inicial da Matemática nessa faculdade?}

Candido da Silva Dias - A Faculdade de Filosofia, Ciências e Letras nasceu no mesmo dia em que foi criada a Universidade de Sáo Paulo - em 25 de janeiro de 1934. Encontrava-me em Mocóca, quándo saiu o decreto do governo estadual. Eu iria cursar o terceiro ano na Escola Politécnica, pois havia nela ingressado em 1932. A FFCL começou com a chegada dos professores contratados em outros países. No caso da Matemática, isso sucedeu precisamente em abril, quando chegou o professor Luigi Fantappié, que era docente em Bologna, Itália. Ele, como os demais professores estrangeiros, foi contratado pelo professor Teodoro Augusto Ramos. Fantappié nasceu no dia 15 de setembro de 1901. Portanto, tinha 32 anos quando assumiu suas funçóes como dirigente da subseção de Matemática da FFCL. Era formado pela Scuola Normale Superiore, de Pisa, onde teve como colega uma pessoa mundialmente conhecida, um dos maiores físicos deste século - Enrico Fermi. Os dois eram amigos.

Năo sei quem aproximou o matemático italiano de Teodoro Ramos, mas foi muito feliz essa contratação, porque Fantappié, embora jovem, possuía uma obra científica respeitável em 1932, pois já havia publicado seus principais trabalhos. Todos eles sáo, sobretudo, relativos à Teoria dos Funcionais Analíticos. Essa teoria é, basicamente, uma criaçáo dele, mas uma extensão da Teoria dos Funcionais, baseada nos trabalhos de Victor Volterra, um grande matemático italiano e autor de boa parte da Análise Funcional da época. Fantappié fora aluno do Volterra e ligado também a outro grande matemático italiano e figura muito importante naquele tempo - o Severı.

Fantappié chegou a São Paulo em circunstâncias um pouco diferentes da dos demais professores estrangeiros contratados para a FFCL. Isto porque inicialmente foi contratado para dar aulas na Escola Poli- 
técnica. A diretoria da Politécnica deu a Fantappié a responsabilidade pelo curso de Cálculo Infínitesimal. Assim, em 1934, a principal atividade dele foi desenvolver esse curso, do qual assisti boa parte na Politécnica. Por que nessa escola? Eis aí um dado curioso. A seção de Matemática da Faculdade de Filosofia só foi definida no fim de 1934. A reitoria da USP, ou a diretoria da FFCL, decidiu que os alunos do curso de Matemática deveriam prestar um exame geral sobre a matéria dada pelo professor Fantappié, naquele ano, na Politécnica.

É nesse momento que propriamente se pode falar em curso de Matemática na FFCL - a subseção, como se dizia na época. Em fins de 1934, Fantappié foi à Itália e em março do ano seguinte estava novamente entre nós, para a realização do exame. Cerca de 10 alunos prestaram esse exame, eu entre eles. Um dos colegas foi Mário Schenberg. Outro, Fernando Furquim de Almeida. Esse exame, realizado precisamente no dia 11 de março de 1935, é que assinala o início do curso de Matemática na Faculdade de Filosofia, Ciências e Letras da USP. Foi um belo exame, diferente, pois Fantappié não tinha nenhuma preguiça, digamos assim, $e$ inquiria sobre toda a matéria dada durante $o$ ano. No meu caso, o exame durou uma hora e vinte minutos.

\section{Palpite ou vocação?}

\section{EA - Por que o senbor náo continuou na Politécnica?}

CSD - Ah, por uma questáo de palpite ou de vocação. Meu pai, que era engenheiro, formado pela Escola Politécnica, tinha razóes sentimentais para que eu nela permanecesse, mas náo opôs a menor objeção a minha transferência para a Faculdade de Filosofia. Pelo contrário, ele achou interessante que eu fizesse a Matemática na nova Faculdade.

Em 1937, fui designado segundo assistente de Fantappié. O primeiro era o professor Omar Catunda. Este se formou na Politécnica em 1931, sendo um engenheiro que se interessava muito pela Matemática. Por isso, desde 1934 o professor Catunda já havia sido escolhido como assistente de Fantappié. O professor Giácomo Albanese chegou ao Brasil em agosto de 1936, para ministrar Geometria, ficando Fantappié somente com Análise Matemática e Análise Superior, pois até entáo acumulava as duas disciplinas, por não haver um professor qualificado para ministrar Geometria.

\section{Nomeado assistente, ainda muito jovem}

$E A$ - Em que ano o senbor se graduou? Na parte de Cilncias, como cra a estrutura da FFCL? 
$C S D$ - Minha graduaçáo foi junto com a primeira turma de toda a Faculdade, em um dia muito festejado - 25 de janeiro de 1937. Essa formatura foi acontecimento memorável, muito bonito, ao qual compareceu Armando de Salles Oliveira, então governador de Sáo Paulo.

Nas áreas de Ciências, tínhamos a Matemática, a Física, a Química e a História Natural. Apesar de a Física e a Matemática estarem bem ligadas, os cursos eram separados. Para a Física foi contratado um professor estrangeiro de grande renome - Gleb Wataghin. Ele chegou aqui, recordo-me bem, um pouco depois de Fantappié, em julho de 1934. Wataghin deu aulas também na Matemática, pois nesta havia a disciplina de Física e ainda a de Mecânica. (As duas disciplinas - Física e Mecânica - eram ministradas pelos docentes da subseçáo de Física, como se dizia na época). As aulas do professor Wataghin nos foram ministradas nas dependências da Escola Politécnica, no segundo semestre de 1934. O professor Giuseppe Occhialini chegou em 1937 ou no ano anterior. Conheci-o bem, mas náo fui seu aluno. No dia $1^{\circ}$ de março de 1937, fui nomeado segundo assistente de Fantappié. Com a belíssima idade de 23 anos!

\section{EA - Em que prédios funcionou o curso de Matemática da Faculdade de Filosofia?}

CSD - As aulas de Fantappié sempre foram ministradas na Escola Politécnica e lá o curso permaneceu até setembro de 1938, numa dependência da Eletrotécnica. Daí passamos para o prédio da Escola Normal (o atual colégio Caetano de Campos), na praça da República. Todo o terceiro andar, que fora reformado, foi cedido à Faculdade de Filosofia. A Matemática da FFCL nunca esteve no casaráo da alameda Glete. Saindo do prédio da praça da República fomos para outro, no bairro do Paraíso, à rua Alfredo Élis, no dia 20 de junho de 1942. A etapa seguinte, em agosto de 1949 , foi a transferência para a famosa sede da Faculdade, na rua Maria Antônia.

EA - As turmas na Matemática contapam com muitos ou com poucos alunos? Qual o relacionamento dessa sefáo com as outras áreas da Faculdade de Filosafia? Em sua opiniaio o que representou a vinda dos professores estrangeiros para a FFCL?

CSD - Na década de 30 as turmas possuíam 10 ou 15 alunos. No início, o curso não era muito procurado, mas nele se matriculavam pessoas com vocação para o estudo da Matemática. Náo mantínhamos contato estreito com a Química ou com a História Natural (Biologia), mas havia uma relação razoável da Matemática com a Física. A Química teve contato mais estreito com a Física, mesmo porque, em certo tempo, funcionaram no mesmo prédio da alameda Glete. 
A presença dos professores estrangeiros na fase pioneira da $\mathrm{Fa}-$ culdade de Filosofia foi decisiva, importante e renovadora. Fantappie, por exemplo, introduziu no Brasil os cursos de Matemática, porque anteriormente, nas escolas politécnicas ou de engenharia, somente se ministrava a parte fundamental do Cálculo Infinitesimal. Fantappié desenvolveu cursos inteiramente diferentes: teoria dos grupos, grupos contínuos, teoria dos números, formas diferenciais aplicadas à análise, análise tensorial (que se denominava, entáo, de cálculo absoluto, como ele dizia).

\section{EA - Em que linguas eram ministradas as aulas e que lipros eram indicados aos alunos?}

CSD - Fantappié dava aulas em italiano, mas aqui devemos relembrar que naquele tempo a influência italiana era muito mais intensa, mais evidente, em São Paulo do que hoje. Assim, as aulas em italiano eram perfeitamente naturais $e$ os alunos não tinham a menor dificuldade. Não me recordo de haver surgido qualquer objeção a esse fato. Em geral, os livros indicados eram editados em italiano, mas também em outros idiomas. Lembro-me bem da fundação da biblioteca da Matemática. Fantappié dedicou-se muito a essa iniciativa. Quando veio da Itália, trouxe muitos livros e coleçōes de periódicos e com essa doação teve origem a biblioteca. Essa contou também com alguns livros que existiam aqui, pertencentes à Politécnica. Quando Fantappié regressou à Itália, em 1939, nossa biblioteca era já apreciável e daí por diante cresceu sempre. Em conseqüência da reforma universitária de 1970, todos os livros relacionados com essa disciplina foram reunidos na biblioteca do Instituto de Matemática que, por isso, tem um acervo razoável em comparação com as bibliotecas das universidades norte-americanas e européias. O que poucos sabem, contudo, é que o impulso inicial para a formação dessa biblioteca foi dado por Luigi Fantappié. Wataghin, no princípio, também dava aulas em italiano, pois havia permanecido alguns anos na Universidade de Turim, na Itália, como professor efetivo. Sua trajetória foi a seguinte: se não me equivoco, nasceu em 1899, na Rússia; por ocasiáo da Revolução de 1917, emigrou para a Itália, onde completou sua formaçáo universitária e fez uma bela carreira como cientista; em Sáo Paulo acabou aprendendo rapidamente o português, o que lhe permitiu usar nosso idioma em suas aulas.

\section{A carreira} $1937 ?$

EA - Qual foi sua trajetória como docente, após sua graduafáo en

CSD - Como já me referi, em março daquele ano fui nomeado 
assistente e Fantappié encarregou-me de desenvolver o curso que era dado aos alunos do primeiro ano. Quando de seu regresso à Itália, eu já estava bem entrosado no curso de Matemática. Os docentes eram Albanese, Catunda, eu e o Furquim, que também foi nomeado assistente. Dávamos aulas de Matemática também no curso de Física. Fiz o doutoramento em 1942. Náo prestei concurso para a livre-docência porque naquele tempo não havia essa preocupação, mas em 1951 ocorreu o meu concurso para a cátedra. Em 1974, fui convidado para dirigir o Instituto de Matemática da unidade da USP em São Carlos e, nesse período, passei também a lecionar na recém-criada Universidade Federal de São Carlos. Aposentei-me em 1978, depois de 42 anos como professor da Universidade de São Paulo. Continuei, porém, como professor da universidade federal. Sempre pensei que poderia lecionar até os oitenta anos, mas em 1990 fui compulsoriamente aposentado, em razão de uma lei federal. Essa é a minha história de mais de meio século como pesquisador e professor de Matemática.

EA - Voltando ao quadro anterior à criaçáo da Faculdade de Filosofia, como era o ensino e a pesquisa em Matemática no Brasil? Tínbamos tradiģăo nessa área?

CSD - No Rio de Janeiro havia alguma tradiçáo e contávamos com alguns bons matemáticos, como Oto de Alencar Silva, que manteve
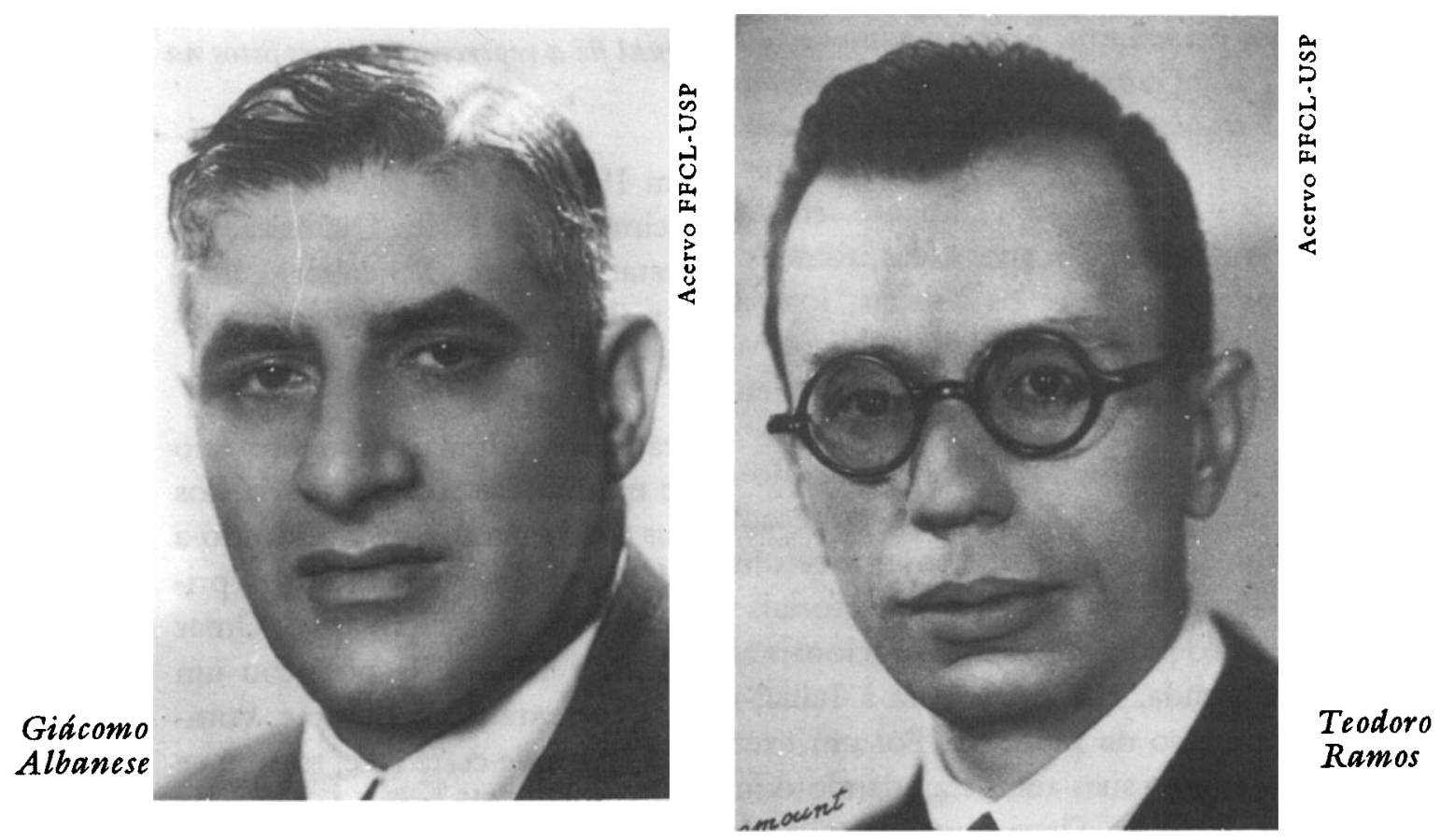
significativa ligação com os franceses. Produziu trabalhos de valor e memórias que foram publicadas no Compte Rendu - importante coleção editada na França pela Academia de Ciências. Na década de 30, portanto, o Rio era mais desenvolvido que Sáo Paulo na minha área. Aqui, só a tradição das aulas de Matemática na Politécnica, pois não havia cursos específicos da disciplina, com uma notável exceção - Teodoro Augusto Ramos. Este se formou no Rio, tendo mantido relacionamento estreito com Manoel de Amoroso Costa, grande matemático que faleceu naquele desastre ocorrido quando da chegada de Santos Dumont ao Brasil. Teodoro Ramos foi catedrático de Mecânica Racional na Escola Politécnica de São Paulo, e destacava-se também por suas pesquisas em Matemática. Posso testemunhar que suas aulas eram magníficas porque fui seu aluno em 1933. Ele e o Amoroso Costa também publicaram trabalhos na França. Teodoro Ramos faleceu muito moço, em 1935. Foi uma personalidade notável, porque, além do mais, revelou-se como bom administrador, tendo sido muito ouvido pelos que governavam nosso estado. Cabe acrescentar que sua atuaçáo foi decisiva para a criação da Universidade de Sáo Paulo e da Faculdade de Filosofia. Ainda mais porque se encarregou da contratação de professores estrangeiros para a FFCL.

\section{O ambiente cultural na década de 20}

$E A$ - Na década de vinte o ambiente cultural brasileiro comefou a sair da pasmaceira. Einstein passou pelo Brasil, em sua viagem a Buenos Aires, a Física Qudntica era a grande nopidade. Qual foi a repercussáo desses fatos na Faculdade de Filosofia, rectm-criada?

CSD - Eu somente senti isso em 1934 e 1935, como aluno de Wataghin. Em suas aulas, tomei conhecimento da Física Quântica. Na pesquisa, entre os colegas, logo se destacou Mário Schenberg. Estimulado por Wataghin, publicou vários trabalhos em revistas estrangeiras. Na Matemática o fato sucedeu mais tarde, com Omar Catunda.

No meu caso, a divulgaçáo de trabalhos originais somente veio depois, em 1951, com a publicação de minha tese sobre a teoria dos funcionais analíticos em que retomo seus fundamentos, identificando-a com a teoria dos espaços vetoriais topológicos. Esse trabalho foi o primeiro publicado sobre funcionais analíticos com orientação atual. Omar Catunda, em férias, fora à Itália, em fins de 1938, e lá publicou um trabalho de pesquisa. Foi um excelente assistente de Fantappié, completando suas aulas e ajudando-o muito. Depois de certa fase, tornou-se o chefe do Departamento, quando Fantappié e Albanese deixaram a 
universidade, dirigindo-o de 1940 até 1962 quando se aposentou (como disse, Fantappié regressou à Itália em 1939 e Albanese três anos depois).

\section{A ameaça}

EA - Em 1937, depois do golpe de Estado de 10 de nopembro, quiseram dissolver a Faculdade de Filosofia. Segundo uma versão, quem salvou a FFCL foi o professor Fantappié, com um discurso que fez perante a direção da USP. O senbor tepe conbecimento desse episódio?

CSD - A tentativa de dissoluçáo da Faculdade de Filosofia era notória. $O$ interventor em São Paulo era Adhemar de Barros, que nomeou para dirigi-la um historiador a quem estava muito ligado - Alfredo Ellis Júnior. Dizia-se, na época, que a missão deste era acabar com a FFCL, inclusive com o curso de Matemática. As coisas caminharam de outro modo porque o professor Éllis Júnior fez um concurso para a cadeira de História do Brasil na FFCL. Devido a esse fato, e a outros, provavelmente, ele passou a defender a Faculdade de Filosofia. A Matemática, de forma particular, foi por ele consolidada.

Não tenho lembrança do discurso do professor Fantappié diante da cúpula da USP em defesa da Faculdade de Filosofia, mas ele desfrutava de enorme prestígio e, certamente, quando se comentava abertamente sobre a possibilidade de dissoluçáo da FFCL, deve ter feito intervençóes oportunas e justas.

\section{A renovação na Matemática}

EA - Nessa sua vivencia de décadas como docente e pesquisador na Universidade de São Paulo que outros dados ttm, em sua opiniడ̄o, um significado notápel na área da Matemática?

CSD - Vou citar um muito importante e que merece ser destacado. Em 1945, a Faculdade de Filosofia contratou como professor visitante um grande matemático e excelente docente - o francês André Weil, que veio dos Estados Unidos. Logo depois foi igualmente contratado outro matemático importante - Oscar Zariski -, de origem russa, cuja história se assemelha à de Wataghin. No ano seguinte, através do intercâmbio mantido com a França, recebemos outra figura de relevo, o francês Jean Dieudonné. Weil e Dieudonné eram membros do grupo Bourbaki, fundado na França, e que renovou a Matemática neste século. O grupo publicou uma obra com mais de vinte volumes. Dieudonné era uma espécie de secretário do grupo e discutia sempre com Weil os trabalhos do Bourbaki. Ficaram na USP por três anos e, os dois, além de Zariski, nos deram aulas inesquecíveis. Entáo, nós, professores 


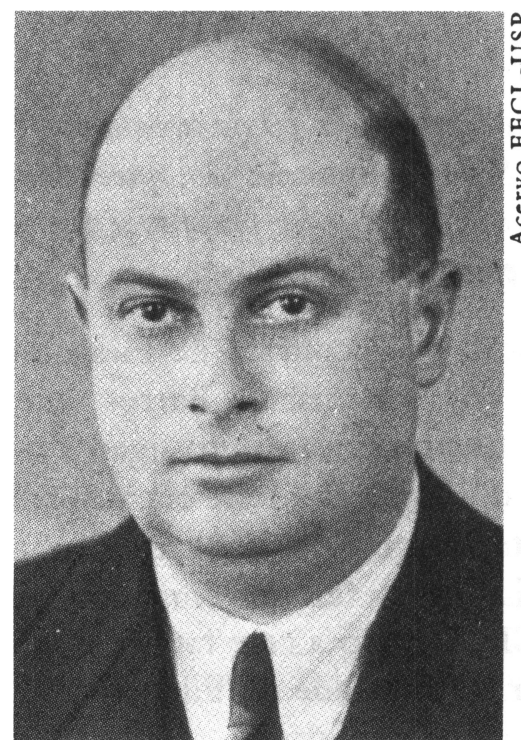

Luigi Fantappié

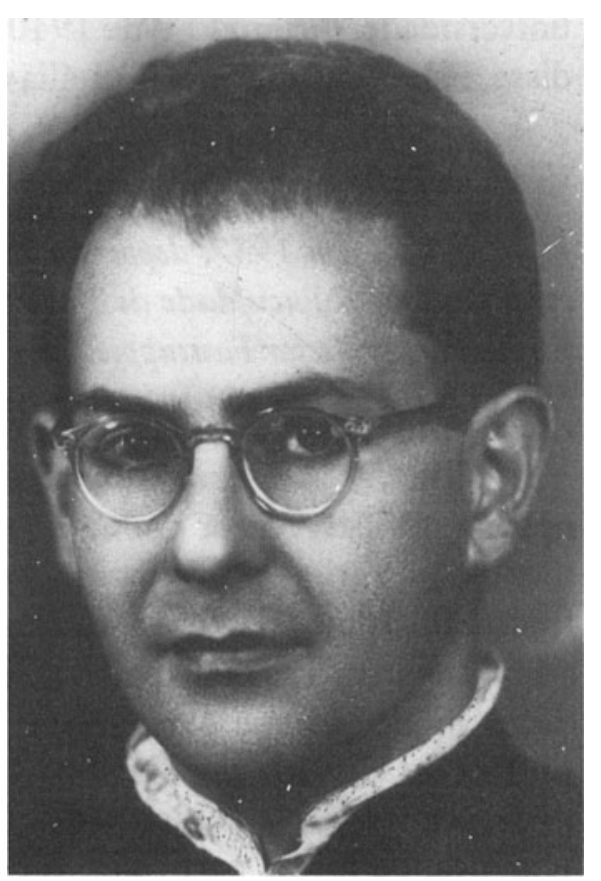

Omar Catunda

brasileiros, tivemos muito cedo conhecimento dessa renovação mundial na Matemática. Esse fato é muito significativo na história da Matemática na Universidade de São Paulo e na renovação e consolidação da própria Faculdade de Filosofia.

\section{A reforma universitária}

EA - Professor, qual sua opiniāo sobre a extinção das cátedras decorrente da reforma universitária de 1970? Foi acertada a saida da Matemática da Faculdade de Filosofia?

CSD - Penso que a extinçáo das cátedras vitalícias não foi um fato muito importante, mas não posso opinar sobre as consequiências daí advindas porque não conheço os resultados dessa mudança para a USP. Acredito que a criação do Instituto de Matemática, fora da Faculdade de Filosofia, foi benéfica para nossa área.

EA - Professor, dando um balanfo, qual a importancia da criagäo da Faculdade de Filosofia, Cilncias e Letras e da Unipersidade de São Pasilo?

CSD - Julgo que esse fato foi importantíssimo e não existe outro mais significativo na evoluçăo científica brasileira. Está relacionado com a grande figura de seu criador - Armando de Salles Oliveira. Essa iniciativa foi inesperada. Eu era aluno da Escola Politécnica e, de vez em 
quando, ouvia falar sobre a viabilidade da fundação da USP. De repente, saiu o decreto constituindo a Universidade. E, dentro dela, uma novidade na vida acadêmica: a Faculdade de Filosofia, Ciências e Letras. Tudo isso em consequiência daquele ato governamental publicado em 25 de janeiro de 1934. Note-se o seguinte: Armando de Salles Oliveira ainda não era governador - apenas interventor federal, nomeado em agosto de 1933. Estritamente, tão só um delegado do Poder Central, portanto, de Getúlio Vargas. Por isso, penso que o Getúlio Vargas tem participação na fundação da Universidade de São Paulo. Aquele decreto foi para valer, tanto assim que, de imediato, houve a decisão de enviar Teodoro Ramos à Europa - França, Alemanha e Itália - a fim de contratar professores para as disciplinas básicas da Faculdade de Filosofia. Como aconteceu isso em táo pouco tempo? Que outro fato tem um valor equivalente? Em resumo, a criaçáo da USP e da Faculdade de Filosofia, Ciências e Letras marcou o início de uma nova etapa na vida cultural do país. 